\title{
A STOCHASTIC ASSESSMENT OF THE EFFECT OF GLOBAL WARMING ON RAINFALL AND AGRICULTURE
}

\section{ENOBONG FRANCIS UDOUMOH, NSIKAN PAUL AKPAN AND INIABASI ETUK}

(Received 25 June 2012; Revision Accepted 31 July 2014)

\begin{abstract}
Crop production depends on rainfall, and rainfall is affected by extreme weather conditions. Markov chain and time series model are adapted for the study of the pattern of rainfall in the North Central Region of Nigeria. Results reveal the long run distributions of the dry and wet days to be 0.7841 , and 0.2159 respectively. The mean return time to dry and wet days is 1.2753 and 4.6318 respectively. Further result reveals that the volume of water due to rainfall is on the increase.
\end{abstract}

KEYWORDS: Global Warming; Rainfall; Markov Process; Time Series; Agriculture.

\section{INTRODUCTION}

The increased frequency of extreme weather events across the globe due to global warming has become a major public concern. Particularly, it is feared that the frequency and intensity of some extreme precipitation events, such as heavy rain and severe drought will increase alarmingly in some areas in the near future due to changes in the patterns of hydrological cycles as global warming progresses, (Kamiguchi et al, 2006). The rise in global average air temperature near the earth's surface was $0.74 \pm 0.18^{\circ} \mathrm{C}\left(1.33 \pm 0.32^{\circ} \mathrm{F}\right)$ during the hundred years ending in 2005. The Intergovernmental Panel on Climate Change (IPCC) projections reveal that average global surface temperature will likely rise further from 1.1

to $6.4{ }^{\circ} \mathrm{C}\left(2.0\right.$ to $\left.11.5^{\circ} \mathrm{F}\right)$ during the twenty-first century, (IPCC, 2001). Both climate models and satellite observations indicate that the total amount of water in the atmosphere and precipitation increased at a rate of about $7 \%$ per Kelvin of surface warming in the last two decades, (Wentz, et al 2007). The consequences of heavy rainfall are evident in wide spread flood incidences around the globe. According to the report of National Wildlife Federation, United States lost over 115 billion USD from 1960 to 2005 in direct damages due to weather and climate disaster which floods and severe storms contributed a significant part (www.nwf.org/globalwarming). According to the National Emergency Management Agency (NEMA), not fewer than 258,000 Nigerians were displaced by flood in 2010 (redskynews.com). The situation was not any better in 2011 as flood incidences were on the increase across the country. Nevertheless, the impact of rainfall on agriculture need not be overemphasized, see Jiduana et. al.(2012), Bello et. al. (2012), Apata(2011). In Nigeria, more than $79 \%$ of the cultivated area is rain fed and much locally produced food comes from such areas, the quantity depending upon the amount and distribution of rainfall. In particular, the North Central region of Nigeria is known for her dependence on agriculture and agricultural products as means of livelihood. An important feature of the rainfall pattern is the timings of the end of the wet season. If this occurs too soon the crop may not have sufficient water to reach maturity. However, excessive wet weather may prevent ripening and harvesting. Hence, projection of future rainfall using past rainfall records is useful in crop planning. Chukwu (1992), Ayinde et. al. (2011), Nwaiwu et. al. (2014),

This study aims at determining the effect of global warming on the pattern of rainfall in the North Central Region of Nigeria in the last three decades using Markov chain and classical time series model. Some contributions on agricultural planning will be made based on the findings.

\section{METHOD}

\subsection{Data}

Daily data on the amount of rainfall measured in millimeter $(\mathrm{mm})$ was collected from the records of meteorological Agency, a department under the Nigerian Air Force Tactical Air Command, Makurdi, Benue State, Nigeria. The data was collected using the appropriate measurement tool known as the Rain gauge. The classification of the wet and dry day is such that any day the amount of rain is measurable by the rain gauge is termed wet day otherwise it is dry. The longitude of this rainfall data was measured at $08^{\circ} 37^{\prime} \mathrm{E}$ and on latitude $07^{0} 41^{\prime} \mathrm{N}$. The height of the station from which all measurement was taken is 106.4 meters. The data cover a period of 30 years (1979-2008). North Central Nigeria comprise of the following states, Benue, Kogi, Nasarawa, Niger, Plateau, Kwara and the Federal capital territory, Abuja. This region has the same climatic condition, namely, the Tropical Savanna climatic, characterized by a minimum temperature of $18^{\circ} \mathrm{C}\left(64^{\circ} \mathrm{F}\right)$ through the year and annual rainfall of about $1500 \mathrm{~mm}$ (59.1 in). Obioha (2009). Hula (2010), Umeghhalu and Okonkwo

(2012).

Enobong Francis Udoumoh, Department of Mathematics/Statistics/Computer Science, University of Agriculture, Markurdi, Nigeria.

Nsikan Paul Akpan, Department of Mathematics and Statistics, University of Port Harcourt, Port Harcourt, Nigeria. Iniabasi Etuk, Department of Mathematics, Usmanu Danfodiyo University, Sokoto, Nigeria. 


\subsubsection{Markov Chain}

Consider a stochastic process $\left\{X_{n} ; n=0,1,2, \cdots\right\}$ that takes on a countable number of possible values. If $X_{n}=i$ then the process is said to be in state $i$ and there is a likelihood that it will transit to the next state $j$ with fixed probability $P_{i j}$. That is,

$P\left\{X_{n+1}=j \backslash X_{n}=i, X_{n-1}=i_{n-1}, \cdots, X_{1}=i_{1}, X_{0}=i_{0}\right\}=P_{i j}$

for all states $i_{0}, i_{1}, \cdots, i_{n-1}, i, j$ and all $n \geq 0$. Such a stochastic process is known as a Markov chain. Equation (2.1) means that the conditional distribution of any future state $X_{n+1}$ given the past states $X_{0}, X_{1}, \cdots, X_{n-1}$ and the present state $X_{n}$, is independent of the past states and depends only on the present state. Our classification of the Dry $(D)$ and Wet $(W)$ periods will results to a 2-state Markov Chain Model with probability of going from a dry state to a wet state $\alpha$ and the probability of going from a dry state to a dry state as $1-\alpha$, the probability of going from a wet state to a dry state as $\beta$ and the probability of going from a wet state to a wet state as $1-\beta$. By matrix representation we have;

$$
P=\quad D\left[\begin{array}{cc}
D & W \\
1-\alpha & \propto \\
\beta & 1-\beta
\end{array}\right]
$$

$P$ denote the matrix of a one step transition probabilities $P_{i j}$ such that $P_{i j} \geq 0$;

$\sum P_{i j}=1 ; i, j=D, W$.It has the property that all its transition probabilities $P_{i j}$ are fixed (stationary) and independent overtime.

In an irreducible ergodic Markov chain the steady state probabilities are defined as

$\pi_{j}=\lim _{n \rightarrow \infty} P_{i j}^{n} ; j=D, W$.

$\pi_{j}$ is the unique nonnegative solution of

$\pi_{j}=\sum_{i=D, W} \pi_{i} P_{i j} ; j=D, W$

$\pi_{j}$ is independent of the initial state $i$.

A direct by-product of the steady-state probabilities is the determination of the expected number of transitions that a Markov Chain, starting in state j, will returns to a state $\mathrm{j}$ for the first time. This is called, the Mean First Return Time or the Mean Recurrence Time, and is computed as $\mu_{j j}=1 / \pi_{j} ; j=D, W$.

Hence, the Mean First return Time for Dry $(D)$ and Wet $(W)$ days are $\mu_{D D}=1 / \pi_{D} \quad$ and $\mu_{w w}=1 / \pi_{w}$ respectively. The expected weather cycle, $E(C)$ is then define as

$E(C)=\mu_{D D}+\mu_{w w}$

The Markov model definitions are due to Ross (1989)

\subsubsection{Time Series Models}

Time series models are adopted to determine the trend of rainfall in the region. For a detail discussion see Janascek and Swift (1993).

We consider the classical additive time series model;

$X(t)=T(t)+S(t)+R(t) ; \forall t$

where $T(t)$ is the trend, $S(t)$ is the seasonal term, and $R(t)$ is the random component.

Our interest is to decompose equation (2.4). We use the moving averages which can be obtained by computing the series of these averages,

$\frac{1}{s} \sum_{j=0}^{s-1} X_{t+j}, \frac{1}{s} \sum_{j=1}^{s} X_{t+j}, \frac{1}{s} \sum_{j=0}^{s+1} X_{t+j}, \cdots$

to smooth the series in order to remove the seasonal effect.

To estimate the trend we fit the simple linear equation,

$Y(t)=a+b X(t) ; \forall t$

where $a$ is the intercept of the trend line, $b$ is the slope of the trend line, and $X(t)$ is the independent variable. By method of least squares we estimate the parameters of equation (2.6) as follows:

$\hat{a}=\frac{1}{n} \sum_{j=1}^{n} Y(t) ;$ and $\hat{b}=\frac{\sum_{j=1}^{n} X(t) Y(t)}{\sum_{j=1}^{n} X(t)^{2}}$.

\section{RESULTS}

In order to capture the effect of season in the Markov estimates, the analysis was done for the entire period running from January to December and also for each quarter of the year. Results are presented in the tables below 
Table 1: A display of Number of transitions with transition probability

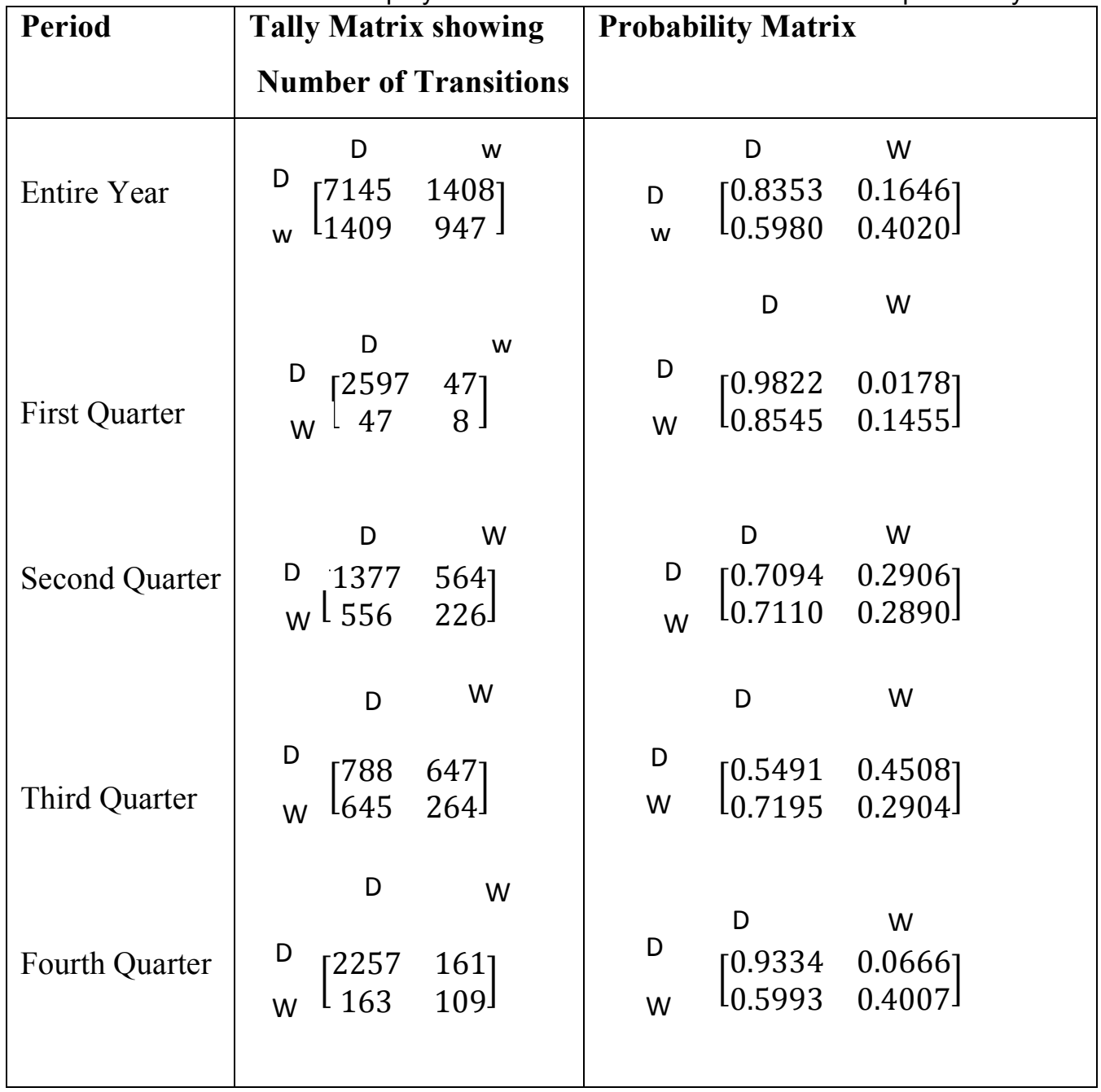

Table 2: Steady state probability, Mean Return Time, Weather Cycles

\begin{tabular}{|l|l|l|l|}
\hline Period & $\begin{array}{l}\text { Steady-State } \\
\text { Probability }\end{array}$ & Mean Return Time & $\begin{array}{l}\text { Expected Weather } \\
\text { Cycle }\end{array}$ \\
\hline Entire Year & $\pi_{D}=0.7841 ; \pi_{W}=0.2159$ & $\mu_{D D}=1.2753 ; \mu_{W W}=4.6318$ & 5.9071 \\
$1^{\text {st }}$ Quarter & $\pi_{D}=0.9796 ; \pi_{W}=0.0204$ & $\mu_{D D}=1.0208 ; \mu_{W W}=49.0196$ & 50.0404 \\
$2^{\text {nd }}$ Quarter & $\pi_{D}=0.7100 ; \pi_{W}=0.2900$ & $\mu_{D D}=1.4085 ; \mu_{W W}=3.4483$ & 4.8568 \\
$3^{\text {rd }}$ Quarter & $\pi_{D}=0.6131 ; \pi_{W}=0.3869$ & $\mu_{D D}=1.6311 ; \mu_{W W}=2.5846$ & 4.2157 \\
$4^{\text {th }}$ Quarter & $\pi_{D}=0.9000 ; \pi_{W}=0.1000$ & $\mu_{D D}=1.1111 ; \mu_{W W}=10$ & 11.1111 \\
& & & \\
& & & \\
& & & \\
\hline
\end{tabular}

Table 1 presents the number of transitions from one state to the other and their corresponding transition probabilities. For instance, the number of transitions from dry state to dry state for entire year is 7145 while its corresponding probability is 0.8353 . The number of transitions from wet to wet state is 947 with corresponding transition probability of 0.4020 . In Table 2 , the steady state probability which describes the weather condition in the long run is presented. For instance, the probability of having a dry day in the North
Central Region of Nigeria is 0.7841 and that of having a wet day is 0.2159 . The mean return time describes the recurrence time of event of dry or wet day. For instance, the recurrence time of a wet day in the first quarter is $\mu_{W W}=49.0196$ which is approximately 49 days. This means that it takes about 49 days after a rainy day to have another rain in the first quarter. Figure 1 shows the graph of quarterly volume of rainfall in the region with evidence of seasonal variation. Using 4-point moving averages the series was smoothened to remove the 
effect of season. The graphs of the actual and smooth series are presented in figure 2. Having removed the effect of season, the trend line was determined. The three graphs for actual, smooth and trend series are presented in figure 3 . The trend shows an upward movement of the line which means a slight increase in the amount of rainfall which may be owing to the effect of

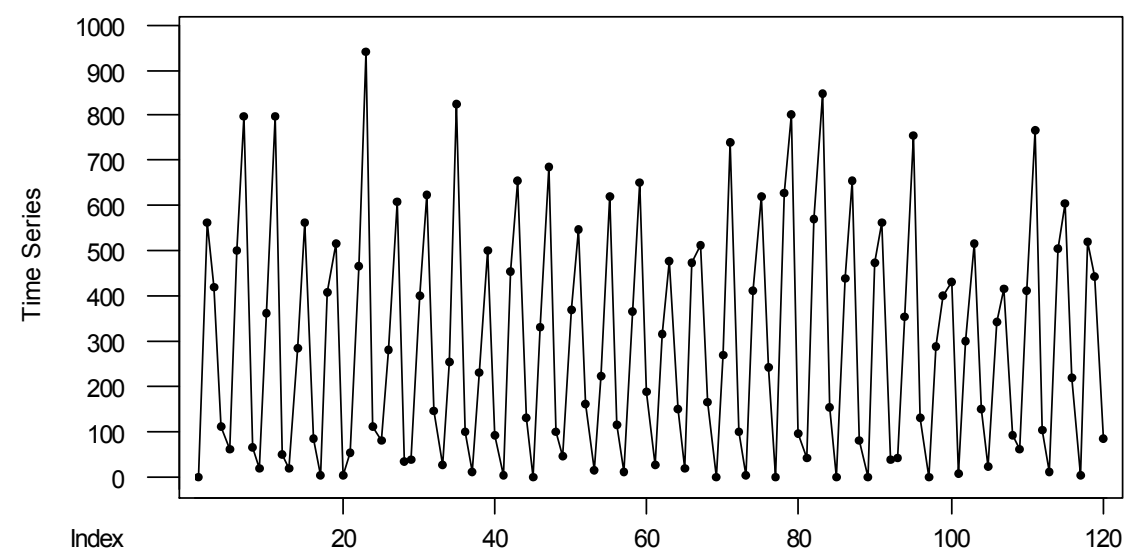

Figure 1: Graph of Quarterly Volume of Rainfall in North Central Nigeria (1979-2008)

\section{Moving Average}
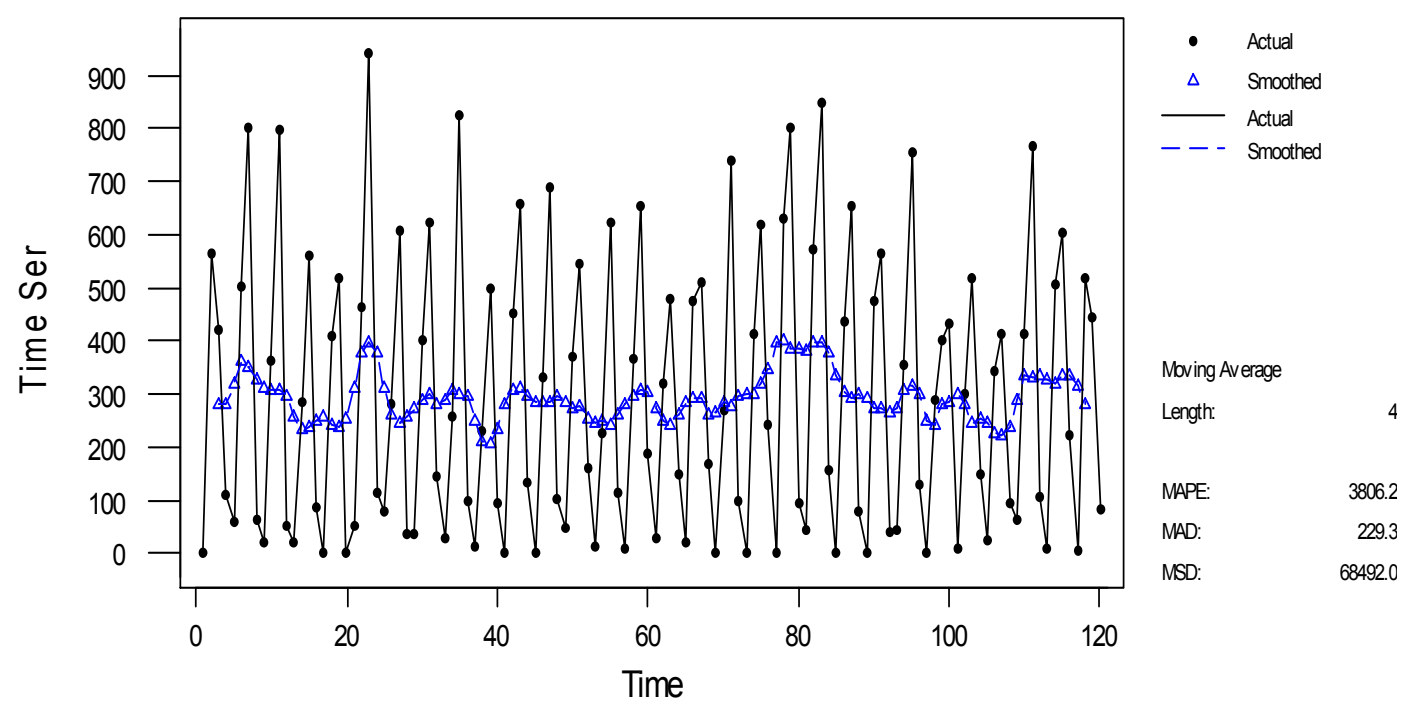

Figure 2: Graph of smooth versus Actual Series 


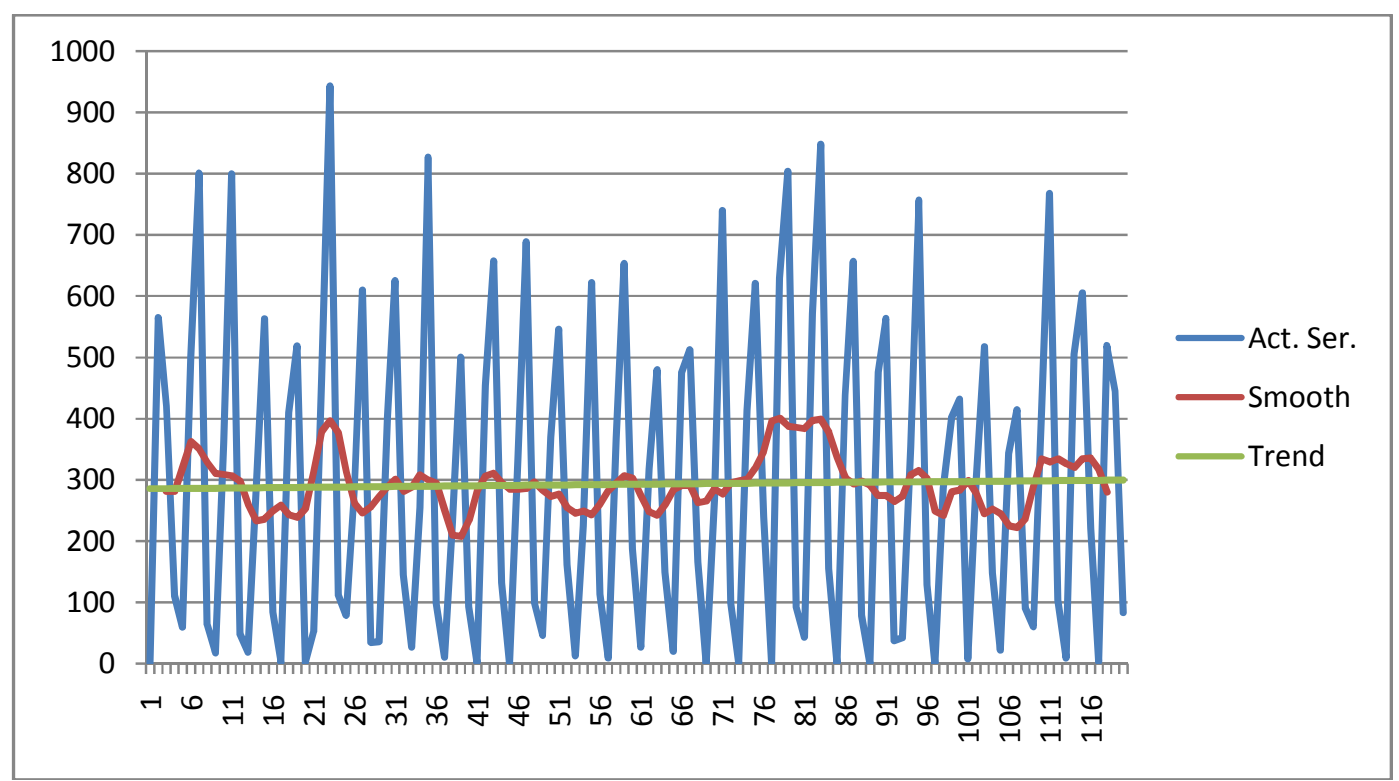

Figure 3: Graph of Actual, Smooth, and Trend Series

\section{CONCLUSIONS}

The time series plots show that the volume of water due to rainfall is on the increase in the region. Despite this anticipated increase in the volume of water owing rainfall, the distributions of dry and wet days have shown that the region is suited for the cultivation of most agricultural crops. Crops like Yam and Cassava could be grown in the first quarter because higher humidity and moist rich soil is best for growth and not wet soil. In the second quarter, it takes about 3 days for rain to return, the following crops could be planted for they are best suited for the rain conditions: Maize, Guinea Corn, Rice, Cassava, Groundnuts, Tomato, Melon and Soybean. This is because; maize and Guinea corn are planted with the instance of rain. Other crops like rice are also planted with the instance of rain as it requires plenty water for cultivation and good growth. These crops can also be grown anywhere even on the steep hill or mountain. Melon can be planted too with a little amount of rainfall as it can retain moisture with its leaves as a cover crop. In the third quarter, the mean return time for rain is about 2 days. This means that there is abundant rainfall. Crops like maize, Rice, Okra, Pepper, Potatoes, Melon and late Soybeans can be planted. Crops that grow well with plenty of moisture or wet soil would yield optimally at this time. In the fourth quarter, crops that do not require too much water for growth could be planted; example, Yam, Cassava, Okra, and Tomato can be grown. In general, the study of the distributions of dry and wet days can be useful for agricultural planning. Although the study period is not very long, the estimates obtained are reliable and in agreement with most popular and recent researches on global warming and rainfall. Hence, caution should be taken to avoid factors that could further heat the earth as this could dangerous to the development of agriculture in the near future.

\section{REFERENCES}

Apata, T. G., 2011. Effects of Global Climate change on Nigerian Agriculture: An Empirical Analysis. CBN Journal of Applied Statistics, 2, (1):

Ayinde, O. E., Muchie, M and Olatunji, G. B., 2011. Effect of global climate change on Agricultural Productivity in Nigeria: A Co-integration Model Approach. J. Hum Ecol., 35, (3): 189-194.

Bello, O. B., Ganiyu, O. T., Wahab, M. K. A., Afolabi, M. S., Oluleye, F., Ig, S. A., Mahmud, J., Azeez, M. A and Abdulmaliq, S. Y., 2012. Evidence of Climate Change: Impacts on Agriculture and Food Security in Nigeria. International Journal of Agriculture and Forestry, 2, (2): 49-55.

Chukwu, W. I. E., 1992. A Markov Chain Model for Crop Planning In Nsukka Environ Using Rainfall Data. E. Afr. Agric. For. J. 57, (4): 253-259.

Hamza, S. A., Jidauna, G. G., Dabi, D. D and Dia, R. Z., 2012. The Effect of Climate Change on Agricultural Activities in Selected Settlements in the Sudano-Sahelian Region of Nigeria. Archives of Applied Science Research, 4, (1): 703-713.

Hula, M. A., 2010. Population Dynamics and Vegetation Change in Benue State, Nigeria. Journal of Environmental Issues and Agriculture in Developing Countries. 2, (1): http://www.redskynews.com. IPCC(2001). Climate Change, International Plant Protection. http://www.gridda.no/climate/ipcc tar/wg1/038.h tml

Janacek, G and Swift, L., 1993. Time Series: Forecasting, Simulation, Applications. Ellis Horwood Limited, New York. 
Kamiguchi, K., Kitoh, A., Uchiyama, T., Mizuta, R and Noda, A., 2006. Changes in Precipitation-based Extremes Indices Due To Global Warming Projected by a Global 20-km-mesh Atmospheric Model. SOLA, 17 2, 064-067.

Nwaiwu, I. U. O., Orebiyi, J. S., Ohajianya, D. O., Ibekwe, U. C., Onyeagocha, S. U. O., Henri-Okoha, A. Osuji, M. V and Tasie, C. M., 2014. The Effect of Climate Change on Agricultural Sustainability in South-East Nigeria-Implications for Food Security. Asian Journal of Agricultural Extension, Economics, and Sociology, 3, (1): 23-36.

Obioha, E. Emeka., 2009. Climaye Variability, Environment Change and Food Security in Nexus in Nigeria. J. Hum. Ecol. 26, (2): 107121.

Ross, S., 1989. Introduction To Probability Models. Academic Press Inc. United Kingdom.

Umeghalu, I. C. E. and Okonkwo, J. C., 2012. Mitigating the Effect of Climate change on Nigerian Agricultural Productivity. Scientific Journal of Agriculture 1(4), 61-67.

Wentz, F., Hilburn, K., Ricciardulli, L and Mears, C., 2007. How Much More Rain Will Global Warming Bring? Science $317,233$. 